\title{
Hemoglobin, Hematocrit, Leukocyte, and Platelet Changes Due To Ultrafiltrationhemodialysis in Chronic Kidney Disease Patients
}

\author{
Nathalya Dwi K.S ${ }^{1}$, Paulus Budiono Notopuro ${ }^{1}$, Yeti Hernaningsih ${ }^{1}$, Widodo ${ }^{2}$ \\ ${ }^{1}$ Department of Clinical Pathology, Faculty of Medicine, Airlangga University/Dr. Soetomo Hospital, Surabaya, Indonesia. \\ E-mail: paulusbudiono@yahoo.com \\ Department of Internal Medicine, Faculty of Medicine, Airlangga University/Dr. Soetomo Hospital, Surabaya, Indonesia. \\ E-mail:wid22@yahoo.com
}

\begin{abstract}
Managing anemia in Chronic Kidney Disease (CKD) patients with hemodialysis (HD) is a challenge to physicians. The present consensus does not address the proper time of blood sampling in HD patients, but higher ultrafiltration (UF) volume (a process of removing fluid excess during HD) may alter hematologic parameters. The objective of this study was to compare some parameters of the Complete Blood Count (CBC); hemoglobin $(\mathrm{Hb})$, hematocrit (Hct), leukocyte (WBC), and platelet counts (PIt) before and after HD. This method was a cross-sectional study performed in the HD Unit, Dr.Soetomo Hospital, including 51 CKD patients selected consecutively, divided into two groups based on the UF volume ( $2 \mathrm{~L}$ and $>2 \mathrm{~L})$. Complete blood count pre- and post-HD were measured using Sysmex XN 1000. The results were 25 males and 26 females in this study, age ranged from 20 to 74 year old, and 36 patients with UF volume $>2 \mathrm{~L}$. Only HD with UF $>2 \mathrm{~L}$ showed significant increases for $\mathrm{Hb}(9.35 \mathrm{~g} / \mathrm{dL}$ to $10.00 \mathrm{~g} / \mathrm{dL})$, Hct (29.80\% to $31.15 \%)$, and Plt (209.00x103/ $\mu \mathrm{L}$ to $213.00 \times 103 / \mu \mathrm{L})$ but WBC did not change significantly. These changes were believed to be caused by ultrafiltration. The conclusion was Hb, Hct, and Plt increased significantly with UF $\geq 2$ L in HD CKD patients.
\end{abstract}

Keywords: Chronic kidney disease, hematocrit, hemodialysis, hemoglobin, ultrafiltration, platelets

\section{INTRODUCTION}

Chronic Kidney Disease (CKD) is defined as abnormalities in the structure or function of the kidney, occurring for three months, which have health implications. In accordance with recommendations from KDIGO 2012. ${ }^{1}$

Chronic kidney disease has now become a global epidemic, and its prevalence has greatly increased worldwide, both in developed and developing countries. The prevalence of CKD reaches $17 \%$ in the United States, whereas in Indonesia, reaches $12.5 \%$ in the adult population. Most CKD patients die from cardiovascular complications, while others reach the terminal stage (CKD grade 5), which requires kidney replacement treatment in the form of hemodialysis $(H D)$, Peritoneal Dialysis (PD), and kidney transplantation. ${ }^{2}$ Currently, there are an estimated 100,000 patients who require kidney replacement treatment in Indonesia, and most undergo hemodialysis. ${ }^{3}$

Ultrafiltration (UF) is the flow of convection (water and solutes) that occurs due to differences in hydrostatic pressure and osmotic pressure, the purpose of eliminating excess water in the blood. ${ }^{4}$

One of the complications of CKD is anemia. USRDS 2010 data in America showed that the incidence of anemia in CKD stages $1-4$ was $51.8 \%$, the average hemoglobin level in the CKD final stage $9.9 \mathrm{~g} / \mathrm{dL}$. In Indonesia, there are no national epidemiological data on anemia in CKD. ${ }^{2}$

Research on a complete blood count test before and after HD has been done before by Mohammed 2008, Alghythan 2012, Pandian 2016, and Al-Hakim 2016. From the results of those studies, there were differences in blood results before and after HD but did not discuss the effect of UF on blood tests.

This research was conducted because there was no research in Indonesia comparing CBC tests before and after hemodialysis. In addition to seeing whether there was an influence of the hemodialysis UF process on hemoglobin, leukocyte, platelet, and hematocrit levels.

The purpose of this research was to know the results of $C B C$ before and after ultrafiltration hemodialysis in CKD patients, to know the difference in the results of hemoglobin, leukocytes, platelets, and hematocrit before and after HD with the amount of UF $(<2 \mathrm{~L}$ and $\geq 2 \mathrm{~L})$. 


\section{METHODS}

This was a cross-sectional observational analytical research. The study was done from May 2017 to September 2017, included. Fifty-three samples from CKD patients undergoing regular hemodialysis at the Dr. Soetomo Hospital Surabaya. Fifty-one samples met the inclusion criteria, two samples were excluded. The patients had filled out an informed consent. Inclusion criteria in this research were CKD patients who had HD 2-3x/week for at least two months and CKD patients who had $\mathrm{HD} \geq 4$ hours. Exclusion criteria were patients undergoing transfusion during HD, CKD patients with bleeding, a clot in the blood sample, the presence of clot on the dialysis membrane.

Subjects who met the inclusion criteria were examined for hemoglobin, hematocrit, leukocytes, and platelets. Three mLs EDTA venous blood samples were taken, and the $C B C$ examination was done with the Sysmex XN 1000. Data were analyzed by SPSS 17.7.

This research had received approval from the Health Research Ethics Committee of Dr. Soetomo Hospital Surabaya with number 436/Panke. KKE/VII/2017.

\section{RESULTS AND DISCUSSION}

The description sample of 51 patients profile could be described that there were more females (51\%) than males (49\%) with ages between 20 and 74 years old (Table 1).

Table 1. Patients profile

\begin{tabular}{cc}
\hline Profile & Result \\
\hline Gender & \\
male & $25(49 \%)$ \\
Female & $26(51 \%)$ \\
Age & \\
Median & $20-74$ \\
Mean $/ x \pm S D$ & $49.71 \pm 11.25$ \\
\hline
\end{tabular}

Descriptions for the results of clinical measurements in 51 sample patients, which included hemoglobin, leukocytes, platelets, and hematocrit values were as seen in Table 2. Since there were groups that were not normal, the method used was a non-parametric Wilcoxon sign rank test.

The following were the results of testing the differences in the measurement of hemoglobin, leukocytes, platelets, and hematocrit before and after UF HD based on the results of testing for four research variables based on the UF results obtained it could be concluded that the values of $\mathrm{Hb}$, leukocytes,
Table 2. Descriptions variable

\begin{tabular}{lcc}
\hline \multicolumn{1}{c}{ Variable } & $\begin{array}{c}\text { Result } \\
\text { Mean } \pm \text { SD }\end{array}$ & Unit \\
\hline Hb & $9.88 \pm 1.66$ & $\mathrm{~g} / \mathrm{dL}$ \\
$\quad$ Before HD & $10.19 \pm 1.95$ & \\
$\quad$ After HD & $7.28 \pm 2.20$ & \\
Leucocyte & $7.00 \pm 2.66$ & \\
$\quad$ Before HD & & \\
$\quad$ After HD & & \\
Platelets & & \\
$\quad$ Before HD & $210.39 \pm 65.90$ & \\
$\quad$ After HD & $226.31 \pm 100.01$ & \\
Hematocrit & & \\
$\quad$ Before HD & $29.88 \pm 5.17$ & \\
After HD & $31.39 \pm 6.11$ & \\
\hline SD. Standard Deviation & & \\
& & \\
\hline
\end{tabular}

platelets, and hematocytes did not show a significant difference after UF HD for UF-values < 2 L. Meanwhile, for the UF-value $\geq 2 \mathrm{~L}$, three variables were concluded, namely $\mathrm{Hb}$, platelets, and hematocytes showing a significant difference after UF ( $p$-value $=0.000 ; 0.008 ; 0.000)$. While the value of leukocyte variables tended to decrease after the UF $H D$, it was concluded that there was no difference in the value after the UF HD was performed in the UF results group $\geq 2 \mathrm{~L}$ (Figure $1 \mathrm{~A}$ and $1 \mathrm{~B}$ ).

In this study, differences in hemoglobin, hematocrit, and platelet values were obtained after UF $>2 \mathrm{~L}$. This increase in value was due to hemoconcentration after hemodialysis. Metry et al. showed that HD induced changes in the hemorheological profile, Hct increased significantly at the end of HD, which caused a significant increase in blood viscosity. When the blood viscosity increased after HD, it could affect the flow in large blood vessels. ${ }^{5}$

Before HD, CKD patients were usually hypervolemic and erythrocytes, $\mathrm{Hb}$, and Hct counts were low, but after ultrafiltration, maximal hemoconcentration was stimulated. ${ }^{6,7}$

In this study, there was a significant increase in platelets. This was different from the results of previous studies, where there was a decrease in platelets after HD. ${ }^{8}$ The possibility of platelets increased in this study was because ultrafiltration caused blood viscosity and plasma viscosity to high predialysis, and increased significantly at the end of $H D$. Increased plasma fibrinogen can cause changes in plasma viscosity, as explained by a significant correlation between changes in plasma viscosity and fibrinogen. ${ }^{6}$ The results of this study were in 

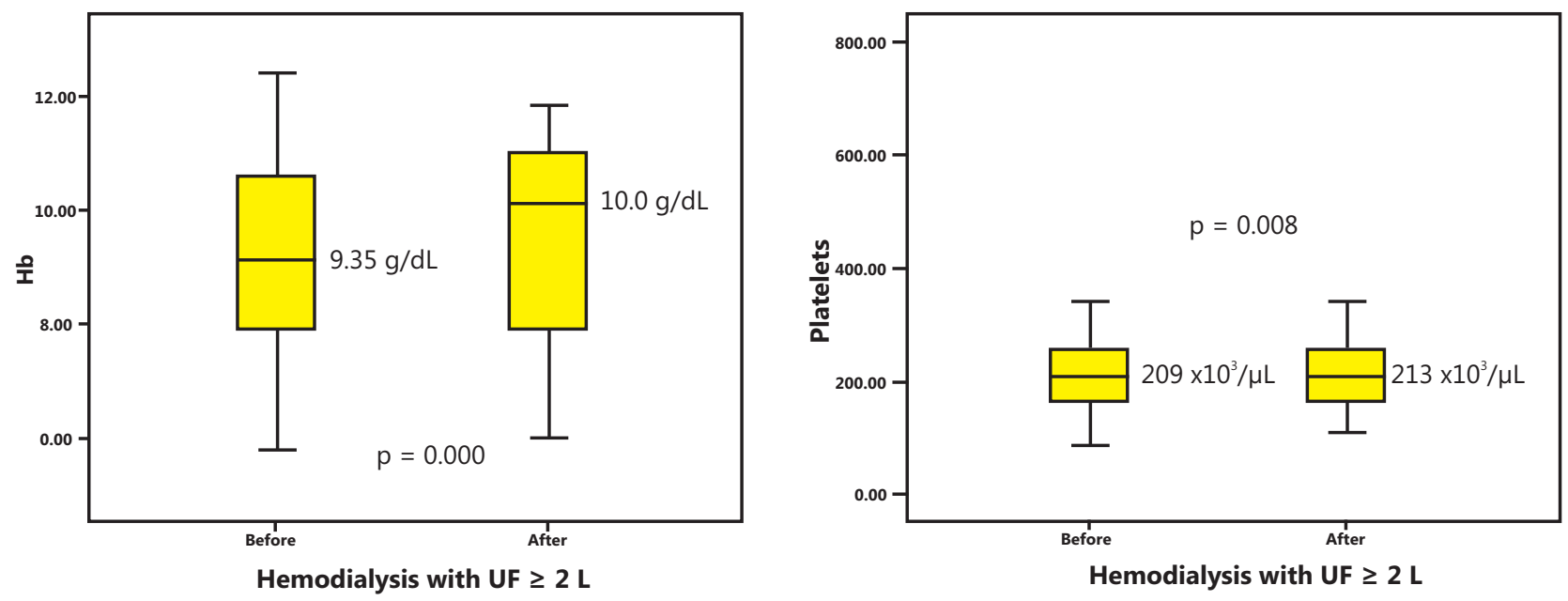

Figure 1A. Block spot hemoglobin and platelets before and after hemodialysis with UF $\geq 2 \mathrm{~L}$
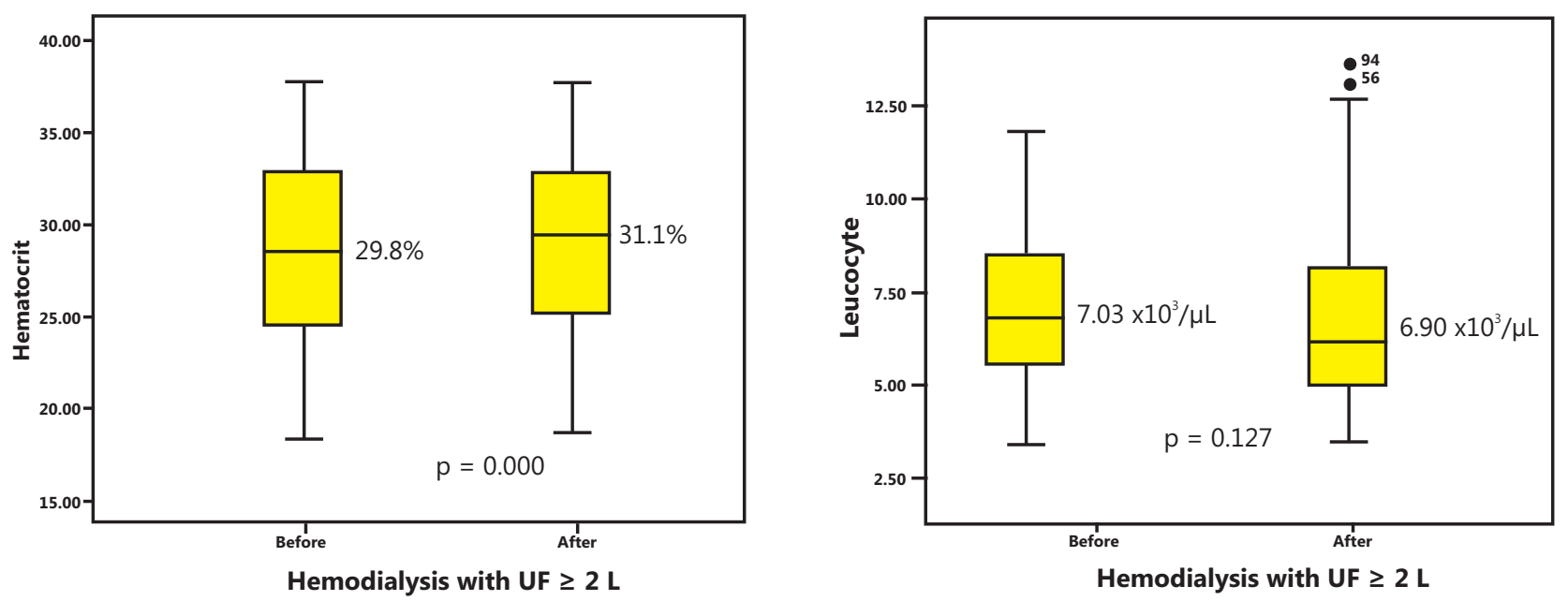

Figure 1B. Block spot hematocrit and leucocyte before and after hemodialysis with UF $\geq 2 \mathrm{~L}$

accordance with Mohammed et al. where no correlation was found between platelet counts with the time period of the patient on dialysis. Partial prothrombin and thromboplastin parameters increased after dialysis. ${ }^{9}$

This study found that the mean leukocytes decreased after HD and was statistically not significant, possibly because there was a movement of leukocytes from the circulating pool to the marginating pool during the HD process. This result was supported by Pandian, showing a decrease in neutrophils and monocytes after HD. ${ }^{10}$ Direct contact between the blood with the dialysis membrane provoked changes in the number of blood cells, a decrease in white blood cells and the number of lymphocytes, stimulation of neutrophil degranulation. In addition, the interaction of granulocytes with dialysis membranes produced Reactive Oxygen Species (ROS) and activated aerobic reactions that caused Oxygen Species (OS). ${ }^{11}$

\section{CONCLUSIONS AND SUGGESTIONS}

There were no significant differences in the value of hemoglobin, hematocrit, leucocytes and platelets after HD with UF $<2 \mathrm{~L}$, and no significant difference for leukocyte values after UF $\geq 2 \mathrm{~L}$, but there were significant differences in the value of $\mathrm{Hb}$, hematocrit, and platelets after HD with UF $\geq 2 \mathrm{~L}$.

This study suggests that a more meaningful CBC examination should be carried out after HD since hemodilution occurred before HD.

\section{REFERENCES}

1. Official Journal of the International Society of Nephrology Kidney International Supplements. 2012; 2: $2 .<$ http://www.kidney-international.org>.pVii 
(accessed at 20 March, 2017).

2. Konsensus manajemen anemia pada penyakit ginjal kronik. Perhimpunan Nefrologi Indonesia. 2011;3-25.

3. Andreas Japar. Pendirian unit hemodialisis di Indonesia. PIT KONKER PERNEFRI 2016; 136.

4. Pakistan Society Nephrology. Mechanism of hemodialysis. http://www.psn.com.pk Copyright 2011 (accessed at 14 March, 2017).

5. Metry G, Adhikarla R, Schneditz D., Ronco C, Levin NW. Effect of changes in intravascular volume during hemodialysis on blood viscoelasticity. Indian J Nephrol, 2011; 21(2): 95-100.

6. Minutolo R, De Nicola L, Bellizzi V, Iodice C, Rubino R, et al. Intra-and post dialytic changes of haemoglobin concentrations in non-anemic haemodyalisis patients. Nephrology Dialysis Transplantation, 2003; 18: 2606-2612.

7. Abdullah Khader Alghythan, Abbas H. Alsaeed. Hematologicalchanges before and after hemodialysis. Scientific Research and Essays, 2012; 7(4): 490-497.

8. Yasir AH Hakim, Abbas AA, Adil Khalil, Hameeda I, Ahmed Mustafa. The Effect of hemodialysis on hemoglobin concentration, platelet count, and white blood cells count in end-stage renal failure. International Journal of Medical Research \& Health Sciences, 2016; 5(5): 22-35.

9. Mohammed Siddig M Ali, Muna Abbas Babiker, Leena Babiker Merghani, Fadlaljabbar Al Taib Ali, Mekki Hamad Abdulmajeed. Hematological changes post-hemo and peritoneal dialysis among renal failure in Sudan. Saudi J Kidney Dis Transpl, 2008; 19(2): 274-279.

10. Pandian J, Amitkumar K, Swaminathan A. Assesment of impact hemodialysis on hematological parameters among patients with chronic kidney disease. Comp Clin Pathol, 2017; 26: 213-218.

11. Hanan Mahmoud Fayed, Samar Sayed Ahmed, Abdel Rahman Abdel El Saied, Al-Lia Safwat. The impact of hemodialysis session on red cells antioxidant enzymes (glutathione peroxidase and reductase) in end-stage renal disease patients undergoing maintenance hemodialysis: Controlled trial (June 28 2016.) Annals of Medical and Biomedical Science, 2016; 2(2): 47-55. 